\title{
IS SOCIAL SOFTWARE A NEW MODE OF SECOND- LANGUAGE LEARNING IN THE INFORMATION AGE?
}

\author{
H. B. Patel \\ drhbeng@gmail.com \\ HNG University, India
}

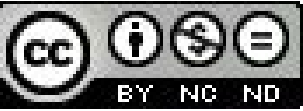

\begin{abstract}
The basic characteristics of social media mirror much of the rhetoric and thinking around educational reform in the modern world context. The basic cultural relevance of social media to young people enables them to learn how to bring their social life into the matrix of school activities. It also provides young learners with different audiences for different activities. Today, social media are probably the critical component in enabling individuals, both teachers and learners, to construct their own personal learning networks. Joining, building, growing and managing digital communities, whether relatively open or relatively closed, enables teachers and learners to connect with others with similar interests and to learn from other participants in those communities.
\end{abstract}

Key words: social learning, social media, information age, information technologies, education, internet, pedagogy

\section{SOCIAL LEARNING}

The core function of learning is acquisition of different types of knowledge. Let us have look at the different traditional means and modes of knowledge acquisition. Acquisition of knowledge is possible in the following ways:

1. Verbal interaction between a teacher and students

2. Non-verbal interaction between a teacher and students

3. Verbal and Non-verbal interaction between a teacher and students

There are other means and modes of learning other than those mentioned above. Social interaction plays a vital role in acquiring knowledge. Social interaction may be:

1. Verbal

2. Non-verbal

3. Verbal and Non-verbal

It is observed that knowledge acquisition through social interaction catches the attention of many educationists as it becomes a part of the curriculum in many areas of learning. Such type of change in approach to learning compels the education community to develop learner centric and interactive curricula at various levels of learning. The essential question is which one of the factors adds fuel to the new mode of learning: social learning. The answer is new development in the field of technology. New type of learning through social media is more beneficial to students than the traditional interactive learning in the class room. The present paper focuses on two points: 
1. How technologically embedded social learning can give good benefit to learners

2. Investigation of the implications of such learning and technology for curriculum development.

An intensive discussion of social learning in the more traditional sense that is learning through physical interaction requiring face-to-face communication and negotiation of meaning is necessarily the prior condition of the discussion of the technological aspect of social learning. Interaction is considered one of the fundamental conditions of learning, so it can be said that the concept of interaction as an essential part of learning and knowledge acquisition dates back to Socrates and can be seen in the works of more recent scholars such as J. Piaget (1970) and L. Vygotsky (1978) among others. Different educationists are shifting their attention to learning as something inextricably social.

The social constructivist perspective on knowledge acquisition has been given prime importance in this study. The theory of social constructivism stresses the importance of social interaction and cooperation when learning takes place. Thus constructivist research examines learners engaged in social practices and cooperative learning to see how such individuals construct meaning out of the input received during interactions. The outcome the theory is that collaborative dialogues give result to knowledge acquisition.

Vygotsky is one of the founding members of social constructivism. His theory and research has become particularly well-known in the field of second-language acquisition. Perhaps Vygotsky has given new term ZPD viz. the Zone of Proximal Development (ZPD). Vygotsky defined the ZPD as: "The difference between the child's development level as determined by independent problem solving and the higher level of potential development as determined through problem solving under adult guidance or in collaboration with more capable peers".

It's observed that in the process of social learning what one understands may be raised by interaction with another person who is operating at a slightly higher level, closing the gap between a learner's existing developmental state and his or her potential development. In short, a student is able to do more with the help of adults or peers than if he or she were alone. Apart from this, social learning gives other advantages such as increased empathy, a sense of belonging, and better communication skills. All of these are supported by a cooperative community that in turn increases a participant's self esteem and consequently further reduces inhibition and other negative factors that may affect an individual who acquires knowledge.

\section{CHARACTERISTICS OF SOCIAL MEDIA}

Social media have some of the following characteristics:

- Social media does not require face to face presence.

- Social media challenges traditional models.

- Social media allows people to communicate.

- Social media allows people to negotiate.

- Social media allows people to edit. 
- Social media allows co-operative learning.

- Social media gives people an audience.

- Social media allows people to collaborate.

- Social media services often remove hierarchy and are built from the bottom up.

- Social media is open and transparent.

The basic questions are:

1. Does achieving all this through the use of social media technology serve a purpose?

2. Is social media technology able to improve the social aspect of learning?

Some of the educationists who favour the traditional approach to learning would argue that technology has nothing to do with learning and it harms the development of a learner. They say that technology takes away the real and tangible dimension of learning, leaving learners isolated and unable to communicate face to face. As a researcher I personally disagree with this point raised by the educationists who favour the traditional approach. I believe that learning through technology does not necessarily mean doing away with the values associated with face-to-face communication. I believe that technology can augment and build on traditional forms of social learning, giving birth to an improved and multifaceted approach to knowledge acquisition.

\section{SOCIAL LEARNING IN THE INFORMATION AGE}

Information and communication technologies (ICT) have vital impact on the new mode of knowledge acquisition. ICI enables to build online communities where people can come together to learn and enrich knowledge cooperatively. It is believed that the Web is already morphing toward a new model, based on social interaction. Thus the Web is now opening a whole new avenue of learning to new generations. Web technology designates the communicative form of the World Wide Web that allows learners to become active members of an online program. Two major advantages are:

1. Members can view the content

2. Members can change and shape it.

We can give an ample number of examples of such technology. It includes such options as social networking sites, weblogs or blogs, wikis, podcasts, etc. Such social software includes currently popular interactive media like Facebook, the online encyclopedia Wikipedia, Hangout, Orkut, Tweeter, Whatsapp, weblog or blog, Viber, WeChat, Youtube, etc.

Social software has one striking feature: the process of communication gives birth to control and structure, not as a result of design, but as an emergent feature of group interaction. The question that arises is how this will be helpful in education. Social software can also be seen as "pedagogical tools that stem from their affordances of sharing, communication and information discovery" (McLoughlin, \& Lee, 2007, p. 666). McLoughlin and Lee define affordance as an "action that an individual can potentially perform in their environment by using a particular tool". 
Such software has the capability to enhance the methods of education. Some educationists believe that judicial use of social software has the capacity to empower learners and provide greater learner control through learner-learner interaction. Learners use the shared online space to build their learning environment collaboratively. The choice made by the teacher to delegate control to the learners, in turn, increases the learners' choices within that context, and their ability to manage structure and dialogue. Timothy E. Worth, a professor of learning technologies at Harvard's Graduate School of Education termed it an "evolution in education," stating that web 2.0 is a major paradigm shift in the way people think. He believes that thinking is now distributed across minds, tools and media, groups of people, and space and time. Learners of today are different because they have access to new forms and modes of learning due to technological change. Today's age is the Information Age, which means that we are living in a time when people have unprecedented access to information and knowledge. The current new generation is too tech savvy and they access and learn information in a manner contrary to traditional top-down teaching methods. The difference is that today's learners, who have plenty of opportunity of access to the Web and who use social software, often construct meaning through bottom-up, self-directed learning approaches. This is called the new mode of learning. Consequently it compels us to redesign curricula according to this new mode of learning. Educationists are currently facing a tidal wave of technologically driven social and economic change that cannot be ignored and for which they consequently must be prepared.

\section{SOCIAL MEDIA IN EDUCATION}

Social media in education is also very important and it is useful to think about the characteristics of social media that we mentioned above and think about how this relates to our classrooms. We need classrooms that challenge traditional models and reverse hierarchy, that allow young people to communicate and collaborate, that provide an authentic audience for children's work and exist within systems that are both open and transparent. It is also important that we understand the impact of social media on privacy and some of the challenges that can be encountered with social media and young people. This includes The Children's Online Privacy Protection Act of 1998 (COPPA) in the USA. While children under 13 can legally give out personal information with their parents' permission, many websites altogether disallow children from using their services due to the amount of paperwork involved. It is for this reason that if a young person under the age of 13 registered to use some of the services listed above then it would be against the websites' terms and conditions.

\section{THE BENEFITS OF SOCIAL SOFTWARE}

The issue of whether social software can really be a beneficial tool for social learning needs to be discussed.

1. Face-to-face group learning in the traditional mode can be difficult to organize with adult learners in particular, and it sometimes fails to meet lear- 
ners' immediate needs, whereas social media learners can get immediate responses within seconds to gain further knowledge.

2. They have plenty of information at their fingertips.

3. Two aspects of teaching and learning were found to be better in terms of social media: interaction and learner-centeredness.

Discussion on social media logs shows an increase in both critical thinking and learner involvement.

Learning in the context of social media that are active, contextual, engaging and student-owned will replace face-to-face classrooms learning experiences in coming years.

Social media allows learners from all over the world both to produce and to consume mold, shape, recombine, and share content collaboratively for the entire world to see and comment on it. Social media makes a suitable tool to support collaborative writing, too.

Social software forms a dynamic forum that fosters extensive practice, learning motivation, authorship, and development of learning strategies. It is an ideal tool for global communication as it can be easily created, accessed, linked, and referenced into other tools. This social matrix has brought learning through interaction to a completely new level where individuals can scaffold on each other in a virtual environment that is continually shifting and turning in a global framework. In such an environment learners may become higher risk-takers with lower inhibitions, allowing for greater confidence in exercising their intellect and their newly acquired knowledge.

In traditional classrooms a difficulty that a teacher may face is how to meet the different needs of all students. All the learners vary in their interests, learning styles, personality, attitude, aptitude and learning strategies. Social software enables students to design the curriculum to meet their own needs in a better way and consequently become more autonomous learners. Along with that the teachers can guide students better by offering more options and designing the curriculum to individual learners' needs. This makes the teachers more stress free to teach a whole class simultaneously at the same level. Social software advocates individualistic approach to learning.

\section{SOCIAl MEDiA - PEDAgOGICAL PRINCIPLES}

\section{Education Reform}

The fact that the same characteristics are also associated with certain strands of thinking about education reform as just as open and transparent as social media requires our attention. Many countries are trying to create classrooms that challenge traditional models and reverse hierarchy, that allow learners to communicate and collaborate, that provide an authentic audience for learners' work, and that exist within systems that are both open and transparent. This means that by embracing the use of social media tools for learning and teaching we can start to build a culture that may help contribute to the reform of our school systems.

\section{Cultural Relevance}

Currently social media is highly culturally relevant for learners and harnessing these tools for education can develop powerful contexts for learning. Lear- 
ners are engaged when they are learning about things or with things that they can relate to or that are relevant to them. Social media is also highly relevant within society.

\section{Real-time Data}

Social media can also be used to collect information and data from students and other key stakeholders. As all experienced educators know, one ingredient of a successful lesson is to try to use up-to-date, real and authentic data rather than contrived data that young people cannot relate to. Tools like SurveyMonkey and Facebook polls provide a great and easy-to-use platform for this.

\section{Collaborative Effort}

Social media tools can also be used to encourage collaboration. Social media can be used to provide real-time collaboration opportunities for students and staff working on word-processing documents, spreadsheets and presentations. Well-managed collaboration on learner projects normally results in an improved output and increased learner pride. Meaningful collaboration is also a vital skill within enterprise education. Social media can equip classrooms with a free ten-seat videoconference solution to allow face-to-face collaboration across continent, time zones and classrooms. Social media video-conferencing tools provide a great opportunity to make it possible for experts to participate in your classes.

\section{Audience}

Social media possess one important characteristic. They provide an authentic audience for learners' work. Writing, re-writing or editing an article about your institute in Wikipedia can become the output of a well-researched cross-curricular project and at the same time it is likely to improve the image/marketing of your institute. This type of task is also hugely empowering for students. Classroom blogs or blogs used as an ePortfolio can also be used to generate audience for young people's work.

\section{INCORPORATING SOCIAL SOFTWARE INTO THE CURRICULUM}

\section{Opportunities for learners:}

1. The importance of group projects discussion forums should be increased to encourage learners' interaction.

2. An interesting thematic structure should be provided so that learners remain engaged in the activities and learning is made more meaningful.

3. Links should be important in the course material to guide learners to outside sources and/or to other parts of the course.

4. It is also important to have quick feedback from faculty and/or peers.

5. Such software needs to be carefully designed and monitored in order to maximize its learning potential.

6. Proper review system for the use of social software may be promoted by examining its actual use, which can be accomplished by reviewing instances of practical applications in current academic practice. 


\section{APPLICATIONS FOR TEACHERS}

Social software is not only applicable to helping students learn interactively and socially but can also be used to assist institutes in designing their curriculum. Creative use of digital tools to present their curricular documents online may eliminate the nuisances of paper-based methods and allow educationists to collaborate on course development and lesson planning. With so many educationists from different parts of the world it becomes difficult to get together for meetings for curriculum design. That is why social software saves time. It is by social software that teachers can easily discuss curriculum issues and exchange ideas.

\section{CHALLENGES OF ADOPTION}

\section{Technical Challenges}

Social media employ a number of different technologies. That is why its adoption is also likely to create many technical challenges. A number of technical problems are dealt with by the co-operation between school management, teachers, parents and ICT departments. Therefore, such cooperation is really important.

\section{No right or wrong}

Social media policy needs to reflect your organisation: who you wish to communicate with and what you feel comfortable doing. Flexibility and context are a key to creating effective social media policies - there are no hard and fast rules to developing one that will serve your purpose, or that of your organisation. It might be better to simply include social media in some of your institution policies and procedures. For example, social media and social networking should be mentioned and included in your school's ICT Policy and your school's Learning \& Teaching Policy. The following list of things/rules to include will help you to develop your own stand-alone policy.

1. Introduce the purpose of social media.

2. Be responsible for what you write.

3. Be authentic.

4. Consider your audience.

5. Exercise good judgment.

6. Understand the concept of community.

7. Respect copyrights and rules of fair use.

8. Remember to protect confidential and proprietary information.

9. Bring value.

10. Productivity matters.

In the state of Victoria in Australia the authority have provided some good social media guidance on their website but have also produced a useful YouTube clip on social media policy that gives examples of what is and is not acceptable.

\section{Challenging Opinion}

Stakeholder opinions may vary when social media are intended to be adopted in a school or institution. Everyone has an opinion when it comes to social media and some of these opinions are more positive than others. People are often 
anxious about change and this anxiety seems to be amplified when the change is occurring because of the adoption of new technologies.

\section{Cultural Challenges}

Change in the culture of an organization is one of the greatest challenges of the adoption of social media in schools. Changing the culture of any organization is very difficult. Even schools and other education institutions are no exception to this. It is absolutely critical when introducing change to any organization to take people (employees, community, parents, external authorities, etc.) with you to the greatest extent possible. To win the hearts and minds of school staff is a fundamental condition if you are serious about introducing social media into your school. The only effective way to do this is to demonstrate its potential for improving the quality of teaching, and its real impact on students' learning. Give clear and concise reasons on why you are keen to see your school adopt social media.

\section{CONCLUSION}

It was noted how closely the basic characteristics of social media mirror much of the rhetoric and thinking around educational reform in the modern world context. Today, the basic cultural relevance of social media to young people enables them to learn how to bring their social life into the matrix of school activities. It also provides young learners with different audiences for different activities. Today, social media are probably the critical component in enabling individuals, both teachers and learners, to construct their own personal learning networks. Joining, building, growing and managing digital communities, whether relatively open or relatively closed, enables teachers and learners to connect with others with similar interests and to learn from other participants in those communities. The policy makers' role is to ensure that schools are given the scope and the capacity to continue to explore how social media can generate a real and discernible improvement in the quality of education. Active consideration of questions of online safety and security, especially for children and young people, should be considered along with the use of social media in learning and education. One of the fundamental problems here is that very many teachers do not themselves fully understand the dynamics and the dangers of the web, and they are, therefore, sadly ill-equipped to pass on good safe practice to their students.

\section{REFERENCES}

McLoughlin, C., \& Lee, M. (2007). Social software and participatory learning: Pedagogical choices with technology affordances in the Web 2.0 era. Proceedings Ascilite Singapore. Retrieved February 10, 2011, from: http:/ / www.ascilite.org.au/conferences/singapore07/procs/mcloughlin.pdf

Mills, B.L. (2007). The next wave now: Web 2.0. Education Digest, 73(4), 4-5.

Piaget, J. (1970). Piaget's theory. In P. Mussen (Ed.), Carmichael's manual of child psychology (pp.703-732). New York: Wiley.

Vygotsky, L. (1978). Mind in society: The development of higher psychological processes. Cambridge, MA: Harvard University Press. 